\title{
2-(3-Benzoylthioureido)-4,5,6,7-tetrahydrobenzo[b] thiophene-3-carboxylic acid ameliorates metabolic disorders in high-fat diet-fed mice
}

Jin ZHANG ${ }^{1}$, Li-na ZHANG ${ }^{2}$, Dong-mei CHEN ${ }^{1}$, Yan-yun FU², Feng ZHANG ${ }^{3}$, Ling-ling YANG ${ }^{1}$, Chun-mei XIA ${ }^{2}$, Hao-wen JIANG ${ }^{3}$, Chun-lan TANG ${ }^{2}$, Zhi-fu XIE ${ }^{2}$, Fan YANG ${ }^{3}$, Jia $\mathrm{LI}^{1,2}$, Jie TANG ${ }^{3, *}$, Jing-ya $\mathrm{LI}^{2, *}$

${ }^{1}$ School of Life Science, East China Normal University, Shanghai 200062, China; ${ }^{2}$ National Center for Drug Screening, State Key Laboratory of Drug Research, Shanghai Institute of Materia Medica, Chinese Academy of Sciences, Shanghai 201203, China;

${ }^{3}$ Shanghai Engineering Research Center of Molecular Therapeutics and New Drug Development, East China Normal University,

Shanghai 200062, China

Aim: Sterol-regulatory element binding proteins (SREBPs) are major transcription factors that regulate liver lipid biosynthesis. In this article we reported a novel synthetic compound 2-(3-benzoylthioureido)-4,5,6,7-tetrahydrobenzo[b]thiophene-3-carboxylic acid (ZJ001) that inhibited the SREBP-1c pathway, and effectively reduced hepatic lipid accumulation in diet-induced obesity (DIO) mice.

Methods: A luciferase reporter driven by an SRE-containing promoter transfected into HepG2 cells was used to discover the compound. Two approaches were used to evaluate the lipid-lowering effects of ZJ001: (1) diet-induced obesity (DIO) mice that were treated with ZJ001 (15 $\mathrm{mg} \cdot \mathrm{kg}^{-1} \cdot \mathrm{d}^{-1}, \mathrm{po}$ ) for 7 weeks; and (2) HepG2 cells and primary hepatocytes used as in vitro models.

Results: ZJ001 (10, 20 umol/L) dose-dependently inhibited the activity of SRE-containing promoter. ZJ001 administration ameliorated lipid metabolism and improved glucose tolerance in DIO mice, accompanied by significantly reduced mRNA levels of SREBP-1C and SREBP-2, and their downstream genes. In HepG2 cells and insulin-treated hepatocytes, ZJ001 (10-40 $\mu \mathrm{mol} / \mathrm{L})$ dose-dependently inhibited lipid synthesis, and reduced mRNA levels of SREBP-1C and SREBP-2, and their downstream genes. Furthermore, ZJ001 dose-dependently increased the phosphorylation of AMPK and regulatory-associated protein of mTOR (Raptor), and suppressed the phosphorylation of mTOR in insulin-treated hepatocytes. Moreover, ZJ001 increased the ADP/ATP ratio in insulin-treated hepatocytes, Conclusion: ZJ001 exerts multiple beneficial effects in diet-induced obesity mice. Its lipid-lowering effects may result from the suppression of mTORC1, which regulates SREBP-1c transcription. The results suggest that the SREBP-1c pathway may be a potential therapeutic target for the treatment of lipid metabolic disorders.

Keywords: 2-(3-benzoylthioureido)-4,5,6,7-tetrahydrobenzo[b]thiophene-3-carboxylic acid; lipogenesis; SREBP-1c; AMPK; mTOR; hepatic lipid accumulation; obesity; metabolic disorders

Acta Pharmacologica Sinica (2015) 36: 483-496; doi: 10.1038/aps.2014.149; published online 16 Mar 2015

\section{Introduction}

Ectopic hepatic lipid deposition is a major point in the development of insulin resistance, nonalcoholic fatty liver (NAFLD), hyperlipidemia, atherosclerosis and other related complications of obesity ${ }^{[1]}$. The mechanisms of ectopic hepatic lipid accumulation are controversial, but the interaction of increased lipolysis, lipid transport or hepatic de novo lipogenesis (DNL) is certainly involved ${ }^{[2,3]}$. One key transcription factor in DNL is sterol regulatory element binding protein $1 \mathrm{c}$

\footnotetext{
* To whom correspondence should be addressed.

E-mail jyli@mail.shcnc.ac.cn (Jing-ya LI); jtang@chem.ecnu.edu.cn (Jie TANG)

Received 2014-10-15 Accepted 2014-12-11
}

(SREBP-1c), which controls hepatic DNL primarily via regulation of the expression of genes involved in DNL, lipid homeostasis and glucose metabolism ${ }^{[4]}$.

There is evidence that lipid deposition is associated with alterations in SREBP-1c expression. Research has confirmed that there is nearly a 5-fold increase in SREBP-1c mRNA in cases of NAFLD compared with healthy controls ${ }^{[5]}$. Yang et al also found similar connections between SREBP-1c and cases consistent with the diagnostic standard of fatty liver ${ }^{[6]}$. SREBP-1c levels are elevated in the fatty livers of obese $(o b / o b)$ mice with insulin resistance and hyperinsulinemia caused by leptin deficiency ${ }^{[7,8]}$. Knebel et al generated mice with liverspecific over-expression of mature human SREBP-1c under control of the albumin promoter and a liver-specific enhancer 
(alb-SREBP-1c). The alb-SREBP-1c mice developed hepatic lipid accumulation featuring a fatty liver by the age of 24 weeks under normocaloric nutrition ${ }^{[9]}$. Mice with germ line deletion of SREBP-1c exhibit diminished fatty acid synthesis in the liver ${ }^{[10]}$. There are three forms of SREBP in mammals: SREBP-1a, -1c and -2. These peptides undergo similar proteolytic activation and share some target genes, SREBP-1a and -1c primarily stimulate fatty acid synthesis, whereas SREBP-2 acts primarily on cholesterol biosynthetic genes and the LDL receptor (LDLR) gene ${ }^{[11]}$. SREBP-1c is synthesized as a precursor that is attached to the endoplasmic reticulum. The mature protein translocates to the nucleus following cleavage and activates transcription by binding to a sterol regulatory element (SRE). Sterols inhibit the cleavage of the precursor, and the mature nuclear form is rapidly catabolized, thereby reducing transcription ${ }^{[12]}$.

SREBP-1c is a target of itself, and it can be induced by the appearance of nuclear SREBP (n-SREBP) in the nucleus ${ }^{[13]}$. Studies have also shown that insulin strongly increases SREBP1c processing to liberate the nuclear form, and it increases the transcription of the SREBP-1c gene, leading to increases in SREBP-1c mRNA and the precursor protein ${ }^{[11]}$. Insulin induces SREBP-1c mRNA by as much as 40 -fold within $6 \mathrm{~h}$ under optimal conditions with freshly isolated rat hepatocytes in cell culture ${ }^{[14]}$. The increase can be blocked by wortmannin, an inhibitor of phosphatidylinositol 3-kinase (PI3K ${ }^{[15]}$, which is an early enzyme in the insulin-signaling cascade. Low concentrations of rapamycin can also block the increase, which indicates that enhanced transcription occurs partially through PI3K/AKT (RAC-alpha serine/threonine-protein kinase)/ mTORC1 (mammalian target of rapamycin complex 1$)^{[16]}$. In addition, insulin stimulation of SREBP-1c processing in hepatocytes requires p70 S6-kinase (p70S6K), which is activated by mTORC1 $^{[17]}$. The insulin pathway bifurcates at AKT. One branch regulates SREBP through the activation of mTORC1; the other branch prevents n-SREBP degradation through glycogen synthase kinase 3 (GSK3). GSK3 phosphorylates n-SREBP, which leads to the ubiquitination and proteasomal degradation of n-SREBP ${ }^{[18,19]}$.

mTORC1 is active under nutrient-rich conditions and inactive under nutrient-poor conditions, whereas AMPK (AMPactivated protein kinase) is activated in the inverse pattern ${ }^{[20]}$. An AMPK is well known as a master energy sensor that maintains whole-body energy homeostasis energy homeosta$\mathrm{sis}^{[21]}$. Activated AMPK in the liver is involved in the regulation of fatty acid oxidation through the phosphorylation of acetyl-CoA carboxylase (ACC), which subsequently leads to a reduction of malonyl-CoA. Malonyl-CoA is an allosteric inhibitor of carnitine palmitoyl transferase (CPT), the key master of the carnitine-dependent transport across the mitochondrial inner membrane and the rate-limiting step of fatty acid $\beta$-oxidation ${ }^{[22]}$. AMPK activation also leads to a concomitant inhibition of fatty acid synthesis and the activation of fatty acid oxidation, partially through its inhibition of the rapamycin-sensitive mTORC1 pathway, which controls SREBP1c transcription. AMPK phosphorylation of the tuberous sclerosis complex 2 (TSC2) tumor suppressor contributes to mTORC1 suppression. Dana M Gwinn reported that AMPK directly phosphorylates the mTOR binding partner regulatory-associated protein of mTOR (Raptor) at two wellconserved serine residues, and this phosphorylation induces 14-3-3 binding to Raptor. The phosphorylation of Raptor by AMPK is required for the inhibition of mTORC1 and cell cycle arrest induced by energy stress ${ }^{[23]}$.

In this study, we used a cell-based luciferase reporter driven by an SRE-containing promoter to identify the compounds that regulate SREBP transcriptional activity, and we hypothesized that inhibition of the SREBP-1c pathway, using a novel small molecule, would lower the risk of obesity-induced comorbidities related to hepatic lipid accumulation.

\section{Materials and methods Cell culture}

Rat hepatocytes were isolated using Selgen's two-step perfusion method ${ }^{[24]}$ and maintained in DMEM. HepG2 cells were cultured in Dulbecco's modified Eagle's medium (DMEM) supplemented with 10\% FBS (Invitrogen, Carlsbad, CA, USA). Culture and differentiation of 3T3-L1 cells were conducted as described previously ${ }^{[25]}$.

\section{Dual-luciferase assay}

HepG2 cells were co-transfected with plasmid pGL2 (Promega, Madison, WI, USA) luciferase reporter plasmids containing a human LDLR promoter $(-355 /+3)$ as the wild-type sterol regulatory element (SRE) or the mutant reporter with disrupted SRE (Addgene, Cambridge, MA, USA) together with the Renilla luciferase reporter plasmid pRL-SV40 (Promega, Madison, WI, USA). Briefly, HepG2 cells were depleted of sterols by incubation in DMEM containing 5\% lipoproteindeficient serum (LPDS, Hyclone, Logan, UT, USA) and 10 $\mu \mathrm{mol} / \mathrm{L}$ compactin (Gene Operation, Ann Arbor, MI, USA) for $16 \mathrm{~h}$. The cells were treated with control DMSO and ZJ001 at the indicated concentrations for $6 \mathrm{~h}$. Then the cells were lysed with reporter lysis buffer (Sigma, St Louis, MO, USA), and luciferase activity was measured according to the manufacturer's protocol.

\section{Lipid synthesis in HepG2 and primary rat hepatocytes}

Primary rat hepatocytes were isolated, cultured as described above, and treated with ZJ001 at the indicated concentrations for $20 \mathrm{~h}$. Cells were pulsed with $\left[2-{ }^{14} \mathrm{C}\right]$ acetate for $4 \mathrm{~h}$. The media was removed, cells were washed three times with cold PBS, and the incorporation of $\left[2-{ }^{14} \mathrm{C}\right]$ acetate was measured as previously described ${ }^{[26]}$.

\section{Measurement of respiration in isolated mitochondria and intact cells}

Respiration measurements in intact cells and isolated mitochondria were conducted at $37^{\circ} \mathrm{C}$ in a Clark-type oxygen electrode (Strathkelvin Instruments, Lanarkshire, UK). Cells or mitochondria were transferred to the electrode chamber. After a steady rate of oxygen consumption had been attained, ZJ001 
was added dose-dependently, and its effect on oxygen consumption was recorded. Mitochondria were isolated from rat liver according to previously reported methods ${ }^{[27]}$. For HepG2 cells, rat hepatocytes and 3T3-L1 adipocytes, respiration measurements were conducted using DMEM; for mitochondria, a standard respiration medium was used ${ }^{[28]}$.

\section{Sulforhodamine B (SRB) cytotoxicity assay}

HepG2 cells were treated with or without the indicated doses of ZJ001 for $24 \mathrm{~h}$, followed by SRB assay, as previously described $^{[29]}$.

\section{Oil Red staining}

3T3-L1 cells were treated with either DMSO or ZJ001 for 7 d during adipogenesis. Next, the cells were fixed in $10 \%$ formalin for $1 \mathrm{~h}$ at room temperature and washed with $60 \%$ isopropanol. The cells were stained with Oil Red for $10 \mathrm{~min}$ at room temperature, followed by washing with distilled water. Images for each dish were captured using a microscope (Olympus Corporation, Tokyo, Japan), and absorbance was measured using a spectrophotometer (Molecular Device, Sunnyvale, CA, USA) at $500 \mathrm{~nm}$.

\section{Animal experiments}

Animal experiments were approved by the Animal Ethics Committee of the Shanghai Institute of Materia Medica. Male C57BL/6J mice (6 weeks old) were purchased from Shanghai SLAC Laboratory Animal Co Ltd. They were housed in a temperature-controlled room $\left(22 \pm 2^{\circ} \mathrm{C}\right)$ with a light/dark cycle of $12 \mathrm{~h}$. After 8 weeks of a high-fat diet (20\% protein, $20 \%$ carbohydrate and 60\% fat, Research Diets, New Brunswick, NJ, USA) to induce obesity, the mice were randomized into various treatment groups based on their body weight and random blood glucose levels. The treatment groups for the 7-week chronic study using intragastric gavage (ig) were as follows: vehicle (0.5\% microcrystalline cellulose) and ZJ001 $\left(15 \mathrm{mg} \cdot \mathrm{kg}^{-1} \cdot \mathrm{d}^{-1}\right)$. Body weight and food intake were recorded daily. After 4 weeks of treatment, and after $6 \mathrm{~h}$ of starvation, the intraperitoneal glucose tolerance test was performed via intraperitoneal injection of $D$-glucose $(1.5 \mathrm{~g} / \mathrm{kg})$. After 7 weeks of treatment, the mice were sacrificed $4 \mathrm{~h}$ after a final dose was administered. The tissues were collected by freezeclamping for further analysis.

Blood glucose was determined using a free-style blood glucose monitoring system (Abbott Laboratories, Chicago, IL, USA). Plasma insulin and leptin levels were measured using ELISA kits (Linco Research, Saint Charles, MO, USA). Plasma triacylglycerol (TG), cholesterol (TC), HDL-cholesterol (HDLc), LDL-cholesterol (LDL-c), lactate and non-esterified fatty acids (NEFA) were assayed using kits from Shanghai FudanZhangjiang (Shanghai, China) and Wako Diagnostics (Richmond, VA, USA). Hepatic and muscular TG contents were measured using Folch's method ${ }^{[30]}$.

\section{Quantitative RT-PCR}

Total RNA was prepared from cultured cells or mouse tissues using Trizol reagents (Invitrogen, Carlsbad, CA, USA). Equal amounts of RNA from individual samples were subjected to quantitative real-time PCR using SYBR green with the Stratagene Mx30005PTM Q-PCR Systems (Agilent Technologies, Santa Clara, CA, USA) according to the manufacturer's protocol. Primer sequences are listed in Supplemental Table S1. All reactions were performed in triplicate. The relative amounts of mRNAs were normalized to GAPDH using the comparative CT method.

\section{Immunoblotting}

Total proteins from tissues or cells were prepared in RIPA buffer $(50 \mathrm{mmol} / \mathrm{L}$ Tris- $\mathrm{HCl}, \mathrm{pH} 8.0,150 \mathrm{mmol} / \mathrm{L} \mathrm{NaCl}, 1 \%$ $\mathrm{NP}-40,1 \mathrm{mmol} / \mathrm{L} \mathrm{Na}_{3} \mathrm{VO}_{4}, 1 \mathrm{mmol} / \mathrm{L}$ DTT, $1 \mathrm{mmol} / \mathrm{L}$ EDTA, $1 \mathrm{mmol} / \mathrm{L}$ EGTA) containing complete protease inhibitors (Roche, Basel, BS, Switzerland). Protein (20 $\mu \mathrm{g}$ per sample) was electrophoresed through SDS-PAGE after boiling for 5 min in SDS loading buffer. The following primary antibodies were used for immunoblotting: rabbit polyclonal antiSREBP-1c IgG-H160 and rabbit polyclonal anti-p70S6K H-9 were purchased from Santa Cruz (Santa Cruz, CA, USA); rabbit polyclonal anti-phospho-SREBP-1c (Ser372), rabbit polyclonal anti-AMPKa, rabbit polyclonal anti-phospho-AMPKa (Thr172), rabbit polyclonal anti-ACC, rabbit polyclonal antiphospho-ACC (Ser79), rabbit polyclonal anti-mTOR, rabbit polyclonal anti-phospho-mTOR (Ser2448), rabbit polyclonal anti-phospho-p70S6K (Ser411), rabbit polyclonal anti-S6, rabbit polyclonal anti-phospho-S6 (Ser235/236), rabbit polyclonal anti-AKT, rabbit polyclonal anti-phospho-AKT (Ser473), rabbit polyclonal anti-Raptor, rabbit polyclonal anti-phosphoRaptor (Ser792), rabbit polyclonal GSK3a/ $\beta$, rabbit polyclonal anti-phospho-GSK3a/ $\beta$ (Ser21/9), rabbit polyclonal-Tuberin/ TSC2, and rabbit polyclonal anti-phospho-Tuberin/TSC2 (Thr1462) were purchased from Cell Signaling Technology (Danvers, MA, USA).

\section{Adenine nucleotide extraction and measurement}

Adenine nucleotides were extracted from cells using perchloric acid and measured using HPLC, as previously described ${ }^{[31]}$. Before the experiment, the culture medium was changed to serum-free medium for $3 \mathrm{~h}$ and DMSO or ZJ001 was added for $1 \mathrm{~h}$. Adenine nucleotides were extracted from cells using perchloric acid and measured using HPLC.

\section{Statistical analysis}

The results represent the means \pm SEM. All the in vitro experiments were conducted at least three times. Differences between two groups were examined using a two-tailed unpaired Student's $t$-test. Differences between multiple groups were compared using one-way ANOVA, followed by an LSD comparison. $P<0.05$ was considered statistically significant.

\section{Results}

ZJ001 down-regulated the transcription activity of the SREcontaining promoter and inhibited DNL in HepG2 cells

The nuclear form of SREBP binds to SRE and directly acti- 
vates the expression of lipogenic genes ${ }^{[32]}$. To identify smallmolecule compounds that inhibit transcriptional activity of SREBP, we transfected a luciferase reporter driven by an SREcontaining promoter into HepG2 cells. These cells were then incubated with compounds, after which luciferase activity was measured. As a positive control, 25-hydroxycholesterol (25HC) dramatically inhibited the reporter activity. Notably, the transcriptional activation of the wild-type LDLR promoter $(-355 /+3)$ was markedly inhibited by a synthesized compound with novel structure, ZJ001 [2-(3-benzoylthioureido)-4,5,6,7tetrahydrobenzo[b]thiophene-3-carboxylic acid] (Figure 1A). Mutation of the SRE motif $(\mathrm{C} / \mathrm{A})$ in the same promoter diminished basal transcription and prevented the further decrease caused by ZJ001, and a similar phenomenon was observed with 25-HC (Figure 1B).

Because ZJ001 was able to inhibit the transcriptional activity of SREBP, we examined the potential of ZJ001 to inhibit DNL by measuring fatty acid and sterol synthesis in HepG2 cells at the indicated non-cytotoxic concentrations (Figure 1C-1E). Regulation of SREBP transcription activity occurs at two levels: transcriptional regulation of SREBP mRNA itself and processing regulation of pre-SREBP protein. We first investigated the mRNA expression of SREBPs and their target genes to elucidate the mechanism that underlies the hepatic lipid contentlowering effect of ZJ001. The results indicated that ZJ001 decreased the mRNA expression of SREBP-2 and SREBP-1c, but not SREBP-1a, in dose-dependent manners. The expression of their target genes, such as fatty acid synthase (FAS), HMG-CoA reductase (HMGCR) and LDLR, respectively, was also inhibited (Figure $1 \mathrm{~F}-1 \mathrm{H}$ ). These results suggested that ZJ001 down-regulated the mRNA of SREBPs and their target genes, which may cause the inhibition of DNL in hepatic cells.
A

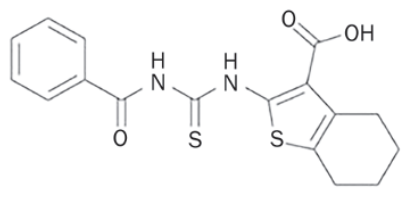

$\mathrm{C}_{17} \mathrm{H}_{16} \mathrm{~N}_{2} \mathrm{O}_{3} \mathrm{~S}_{2} \quad M_{\mathrm{W}}=360.5$
B

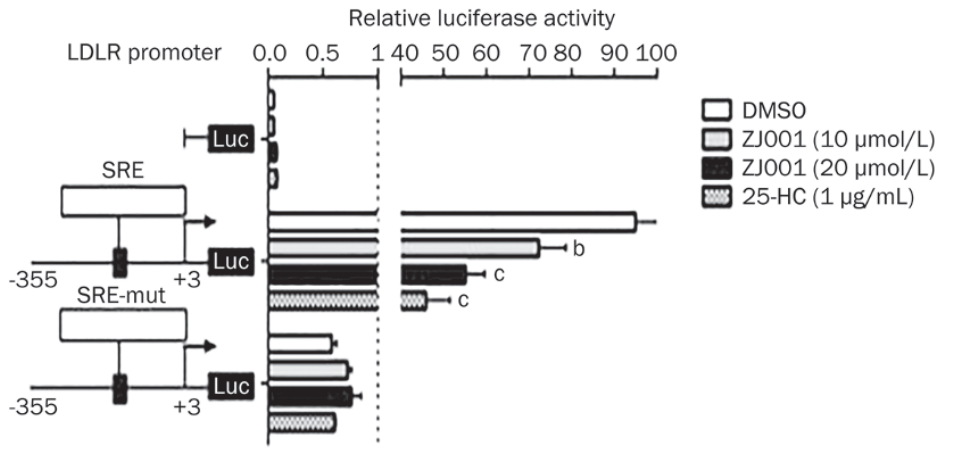

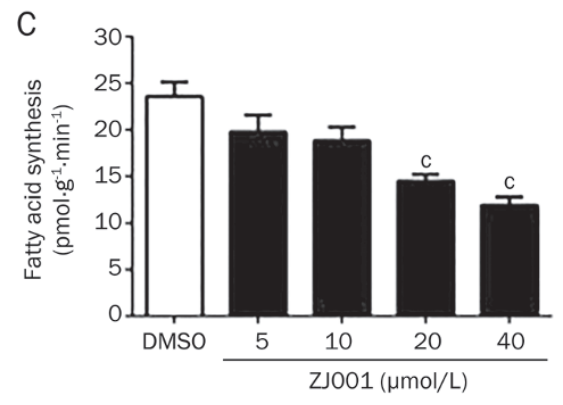

$\mathrm{F}$

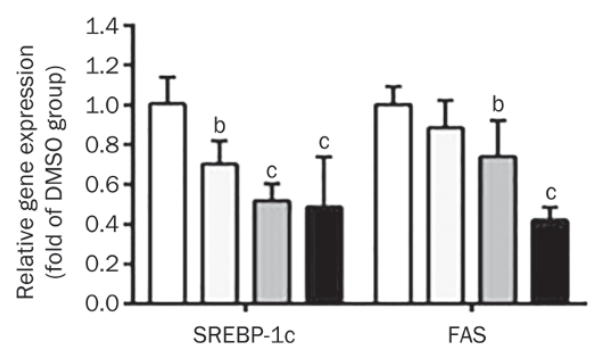

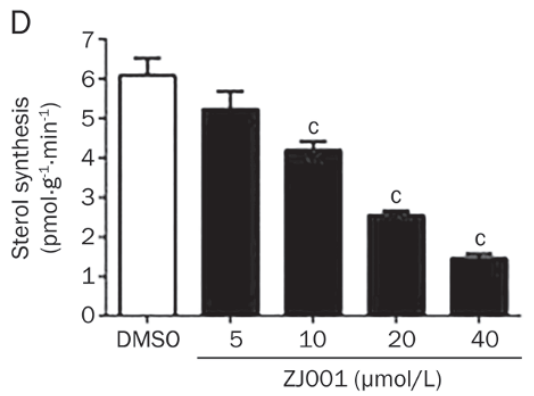

G

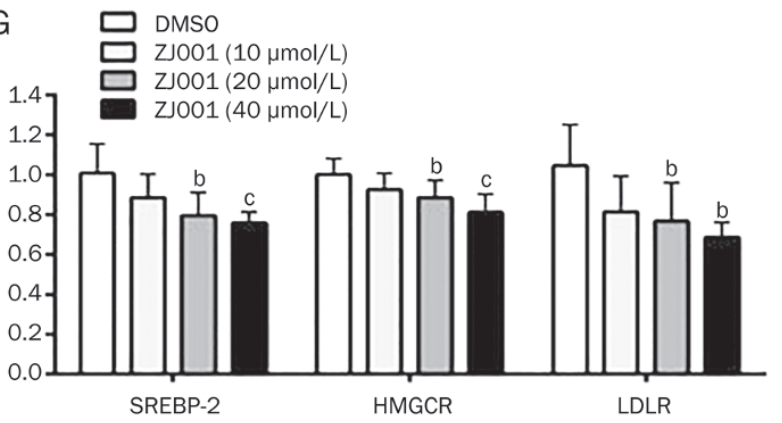

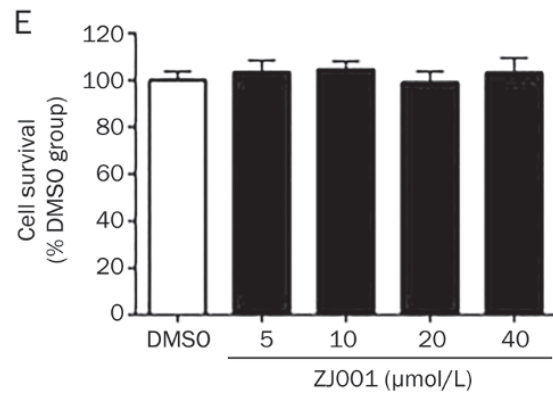

$\mathrm{H}$

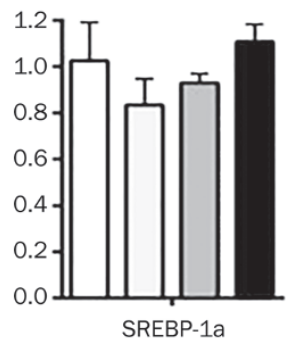

Figure 1. ZJ001 inhibited the biosynthesis of cholesterol and fatty acid by decreasing SREBP target genes in HepG2 cells. (A) Chemical structure of ZJ001. (B) ZJ001 down-regulated the activity of an SRE-containing promoter. (C-E) ZJ001 inhibits de novo lipid synthesis. Measurements of fatty acid (C) and cholesterol (D) synthesis by ZJ001. (E) Cell survival results by multi-dose of ZJ001 treatment. (F-H) Gene expression changes in HepG2 cells with ZJ001 treatment. The results are shown as the mean \pm SEM $(n=3) .{ }^{b} P<0.05,{ }^{c} P<0.01$ compared with the control group. 
ZJ001 ameliorated metabolic disorders in diet-induced obese mice

C57BL/6J mice fed fat-rich diets become obese and insulinresistant and develop moderate hyperglycemia that mimics high-calorie-diet-induced obesity (DIO). To test the chronic effects of ZJ001 on obesity and other comorbidities in vivo, we treated the DIO mice with ZJ001 at a dose of $15 \mathrm{mg} \cdot \mathrm{kg}^{-1} \cdot \mathrm{d}^{-1}$ or vehicle by oral gavage for 7 weeks. The distribution of ZJ001 in tissues and plasma $2 \mathrm{~h}$ after administration of $15 \mathrm{mg} / \mathrm{kg}$ demonstrated that ZJ001 had a favorable tissue distribution in the liver of C57BL/6J mice $(6.9 \mu \mathrm{mol} / \mathrm{L}$, Figure S1), which suggests that $15 \mathrm{mg} \cdot \mathrm{kg}^{-1} \cdot \mathrm{d}^{-1}$ may be active in vivo. The two groups of mice showed similar food intake during the treatment. However, obese mice treated with ZJ001 had gained markedly less weight (49\%) than those in the vehicle-treated obese group at the end of the 7th week (Figure 2A-2C).

Atherosclerosis is characterized by elevated plasma cholesterol and a high LDL-c/HDL-c ratio ${ }^{[33]}$. Our model successfully reproduced this tendency, as indicated by the result that the plasma cholesterol level and LDL-c/HDL-c ratio in obese
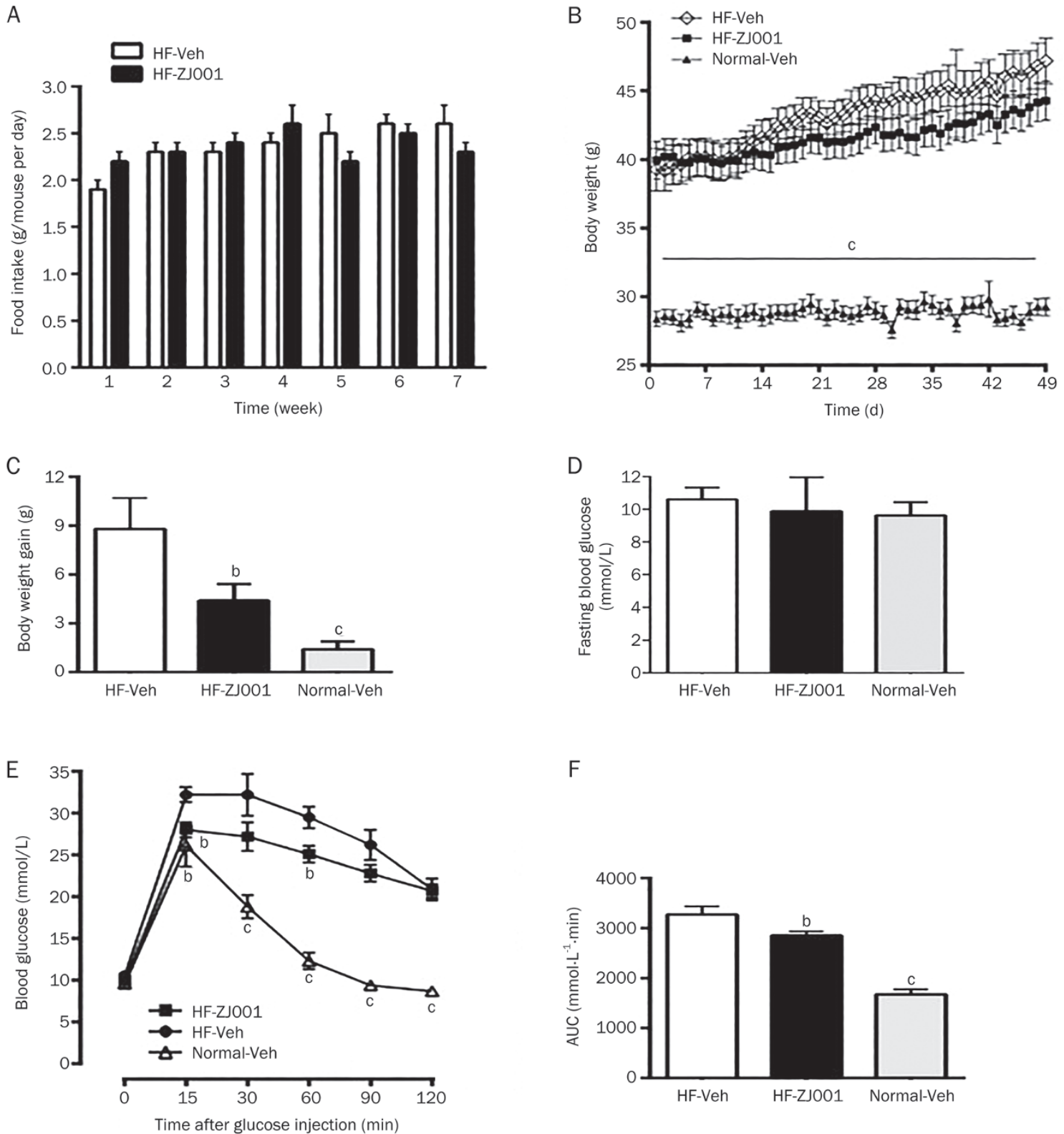

$\mathrm{F}$

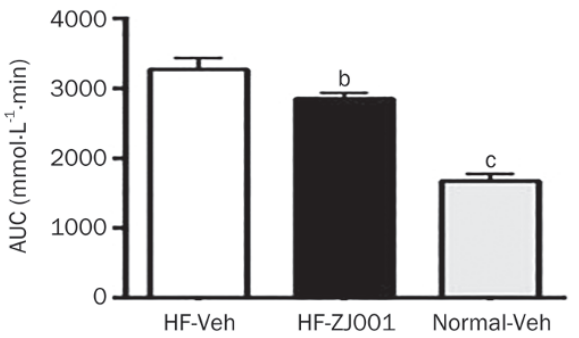

Figure 2. ZJ001 ameliorated metabolic status in high-fat-diet-fed mice. Vehicle and ZJ001 (15 mg.kg $\left.\cdot \mathrm{d}^{-1}\right)$ was administered to mice via oral gavage twice daily. The mice were sacrificed after 7 weeks of treatment and subjected to various analyses. (A and B) Food intake and body weight per mouse during the 7-week experiment. (C) The increase in body weight per mouse after 7-week treatment. (D) Fasting blood glucose level on the 4th week of treatment after 6-h starvation. (E) Effect of Z 1001 on glucose tolerance in mice fed a high-fat diet, as determined by the glucose tolerance test. (F) Quantification of the area under the curve (AUC) from the glucose tolerance test. Error bars represent mean \pm SEM $(n=6-8)$. ${ }^{b} P<0.05,{ }^{c} P<0.01$ compared with the HF-Veh group. 
mice were more than twice those in mice fed normal chow. Plasma parameter analyses showed that ZJ001 significantly decreased plasma cholesterol (TC) by 16\% and LDL-c/HDL-c ratio by $24 \%$, indicating that ZJ001 may potentially reduce the risk of atherosclerosis. Meanwhile, the liver weight of the ZJ001 treatment group was decreased, and the TC and TG contents in the liver of ZJ001-treated mice were lower than those in vehicle-treated mice, suggesting that ZJ001 may have improvement on fatty liver (Table 1).

ZJ001 treatment caused a significant reduction in perirenal, subcutaneous and epididymal fat pad weight, but plasma NEFA was not altered after ZJ001 treatment (Table 1). These results suggest that fat pad loss in white adipose tissue does not occur through triglyceride lipolysis. Furthermore, ZJ001 had no direct effect on adipogenesis in 3T3-L1 cells (Figure S2A), and $\mathrm{O}_{2}$ consumption was not affected by ZJ001 in 3T3-L1 adipocytes (Figure S2B). These data may indicate that ZJ001 ameliorated metabolic disorders in DIO mice through an improvement in ectopic hepatic lipid deposition and that the effects on fat pads may be a feedback effect of chronic treatment.

Furthermore, we investigated whether ZJ001 improved glucose metabolism in vivo. The intraperitoneal glucose tolerance test was performed at the 4 th week of treatment. The results showed that ZJ001 treatment significantly improved glucose tolerance capacity as evidenced by the significantly lower blood glucose levels at $15 \mathrm{~min}$ and $60 \mathrm{~min}$ post-glucose injection and the area under the curve of $0-120 \mathrm{~min}$, but it had no effect on fasting blood glucose level (Figure 2D-2F).

\section{ZJ001 regulated the expression of metabolic genes in vivo}

Consistent with previous reports ${ }^{[34-36]}$, we observed that the mRNA levels of SREBP-1c and SREBP-2, and their target genes, were increased in the liver of long-term high-fat-dietfed mice. The beneficial effects of ZJ001 on metabolic parameters were reflected by its effects on gene expression changes in the liver of mice. SREBP-2 primarily controls cholesterol homeostasis by activating genes required for cholesterol synthesis and uptake. ZJ001 treatment reduced hepatic SREBP-2 mRNA levels. Consequently, the mRNA levels of genes involved in cholesterol biosynthesis, including HMGCR, HMG-CoA synthase (HMGCS), and squalene synthase (SS), were reduced in the liver of ZJ001-treated mice (Figure 3A). SREBP-1c preferentially regulates the lipogenic process by activating genes involved in fatty acid and triglyceride synthesis. ZJ001 significantly decreased the mRNA of SREBP-1c and its target genes, including FAS and ATP-citrate synthase (ACS) (Figure 3B). SREBP-1a is expressed constitutively at low levels in the liver and most other tissues of adult animals. SREBP$1 \mathrm{a}$ is a potent universal activator of all SRE-responsive genes. Similarly, ZJ001 treatment did not alter the mRNA of SREBP1a (Figure 3C), which was consistent with the in vitro effect in HepG2 cells. Moreover, the mRNA levels of genes involved in fatty acid oxidation, such as peroxisome proliferator-activated receptors a (PPARa) and long-chain acyl-CoA dehydrogenase (LCAD) were slightly decreased, suggesting that ZJ001 may reduce fatty acid synthesis and attenuate lipid oxidation (Figure 3D). However, ZJ001 treatment increased the mRNA of uncoupling protein 2 (UCP2) (Figure 3D). ZJ001 significantly decreased genes in carbohydrate metabolism, such as glucose6-phosphatase (G6Pase) and phosphoenolpyruvate carboxykinase (PEPCK) MRNA, without altering the expression of pyruvate dehydrogenase kinase isoform 4 (PDK4) (Figure 3E).

\section{ZJ001 decreased SREBP mRNA and inhibited DNL in hepato- cytes.}

To further investigate whether the beneficial effects caused by ZJ001 in vivo were related to the SREBP pathway, we utilized primary hepatocytes to dissect the underlying mechanism. Hepatic lipid synthetic processes are controlled reciprocally by insulin and glucagon. Insulin stimulates lipid synthesis in hepatocytes chiefly by increasing the mRNA and the

Table 1. Chronic effects of ZJ001 on metabolic variables in DIO mice.

\begin{tabular}{|c|c|c|c|}
\hline & HF-Veh & HF-ZJ001 & Normal-Veh \\
\hline Liver (g) & $1.63 \pm 0.11$ & $1.41 \pm 0.06^{b}$ & $1.36 \pm 0.04^{b}$ \\
\hline Epididymal fat (g) & $2.61 \pm 0.14$ & $2.26 \pm 0.09^{b}$ & $0.33 \pm 0.06^{c}$ \\
\hline Perirenal fat (g) & $1.96 \pm 0.12$ & $1.39 \pm 0.09^{c}$ & ND \\
\hline Subcutaneous fat (g) & $2.81 \pm 0.17$ & $1.52 \pm 0.23^{c}$ & ND \\
\hline Hepatic triacylglycerol( $\mu \mathrm{mol} / \mathrm{g})$ & $54.57 \pm 1.43$ & $49.21 \pm 2.52^{b}$ & $15.19 \pm 0.79^{c}$ \\
\hline Serum cholesterol (mmol/L) & $4.15 \pm 0.13$ & $3.45 \pm 0.25^{b}$ & $1.86 \pm 0.13^{c}$ \\
\hline Serum NEFA (mmol/L) & $0.68 \pm 0.05$ & $0.77 \pm 0.05$ & $0.91 \pm 0.06^{b}$ \\
\hline Serum-HDL-C (mmol/L) & $1.51 \pm 0.04$ & $1.65 \pm 0.08$ & $1.67 \pm 0.11$ \\
\hline Serum-LDL-C (mmol/L) & $3.07 \pm 0.13$ & $2.51 \pm 0.21^{\mathrm{b}}$ & $0.88 \pm 0.15^{c}$ \\
\hline Serum insulin (ng/mL) & $1.04 \pm 0.10$ & $1.03 \pm 0.08$ & $0.73 \pm 0.02^{b}$ \\
\hline
\end{tabular}

Data represent the mean \pm SEM of six to eight mice. Mice were induced into obesity after 8 weeks on high-fat diet and treated with vehicle or ZJ001 orally at a dose of $15 \mathrm{mg} \cdot \mathrm{kg}^{-1} \cdot \mathrm{d}^{-1}$ for 7 weeks. Mice were fasted for $6 \mathrm{~h}$ before collecting the blood samples. ${ }^{\mathrm{b}} P<0.05$, ${ }^{\mathrm{c}} P<0.01$ compared with $\mathrm{HF}-\mathrm{Veh}$ group. ND, not determined. 
A
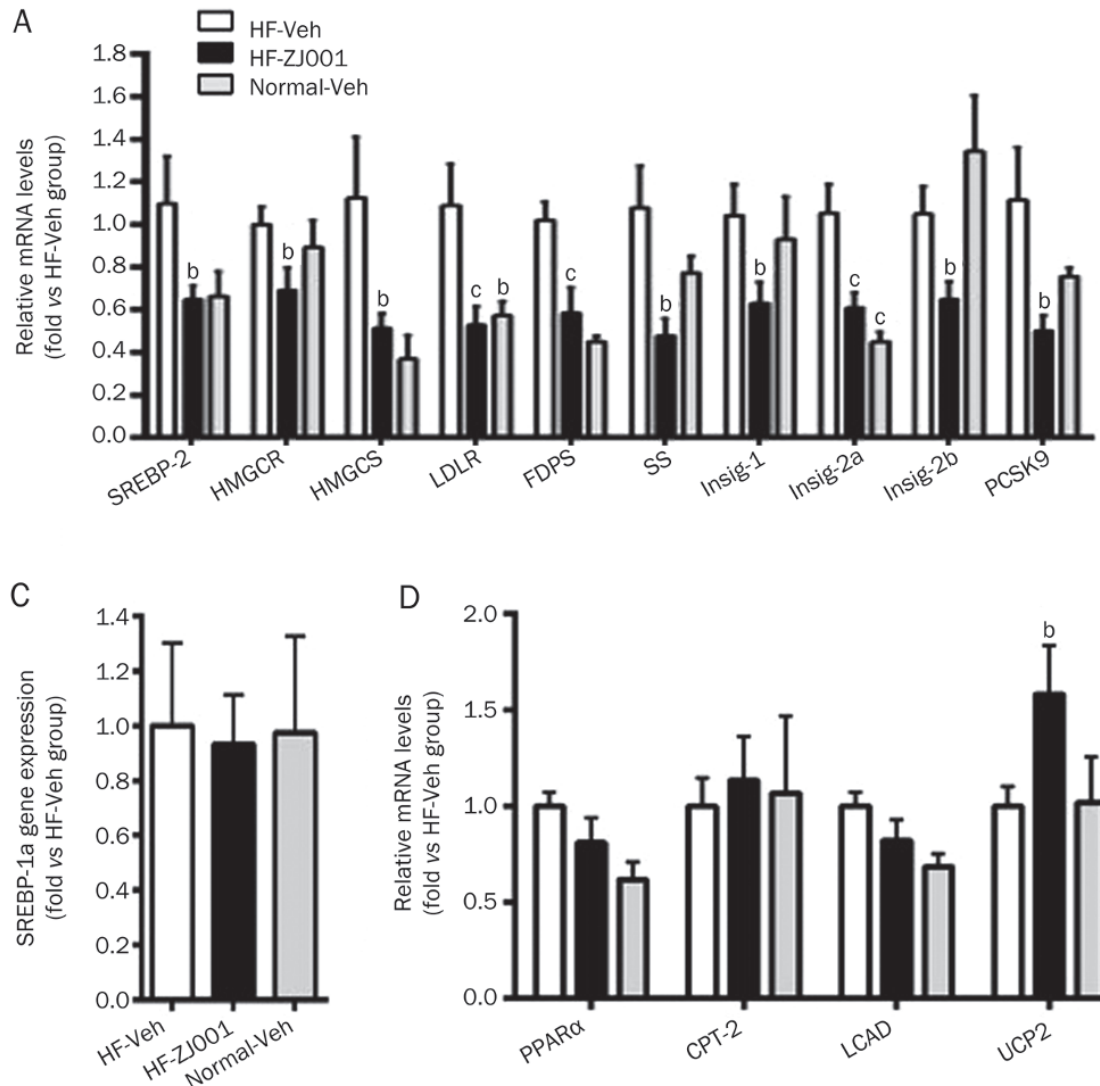

D

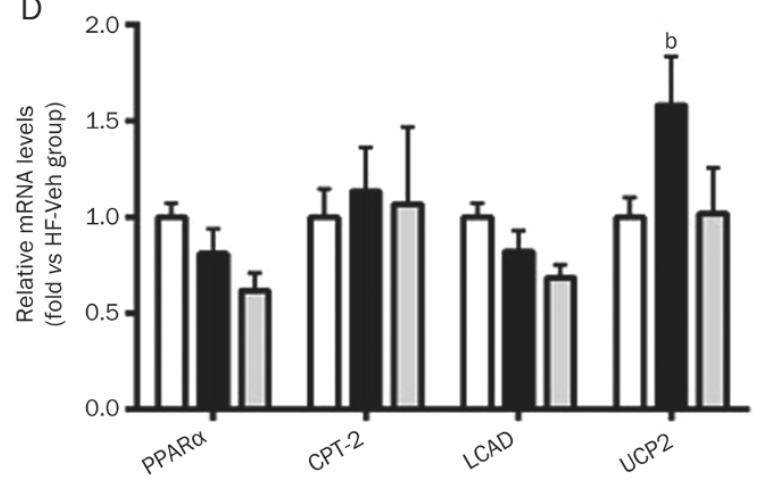

B

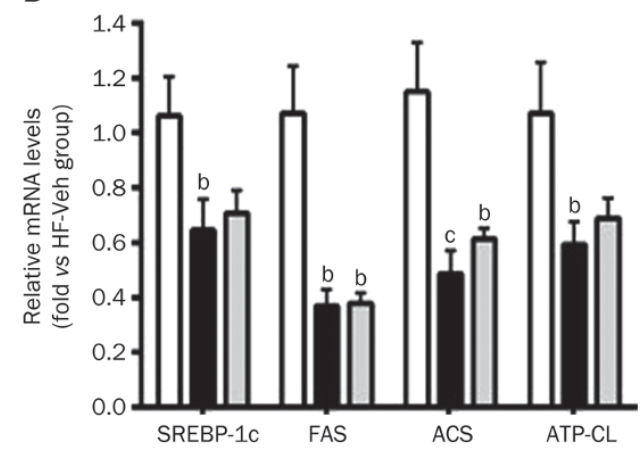

$\mathrm{E}$

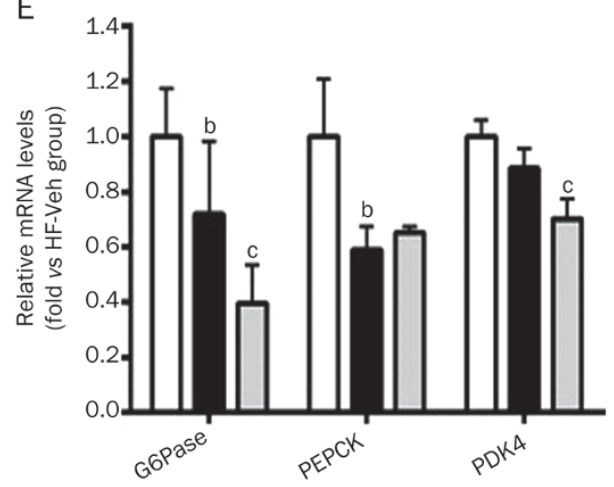

Figure 3. Changes in mRNA levels in liver of the mice treated by ZJ001. The mice used here are the same as those used in Figure 2 . The high-fat-dietfed mice received vehicle and $15 \mathrm{mg} \cdot \mathrm{kg}^{-1} \cdot \mathrm{d}^{-1}$ of ZJ001 were used in analyzing gene expression. For each mouse, equal amounts of total RNA from the liver tissues were subjected to Q-PCR quantification as described in Experimental Procedures. Mouse GAPDH was used as the control. Values represent the amount of mRNA relative to mice fed a high-fat diet in each experiment, which is arbitrarily defined as 1. (A-C) The mRNA level of genes involved in lipid synthesis. (D) The mRNA level of genes involved in fatty acid oxidation. (E) The mRNA level of genes involved in carbohydrate metabolism. The results are shown as the mean \pm SEM $(n=6-8) .{ }^{b} P<0.05,{ }^{c} P<0.01$ compared with the HF-Veh group.

processed nuclear form of SREBP-1 $1 \mathrm{c}^{[37]}$. Hence, we used rat primary hepatocytes to determine whether ZJ001 suppressed the insulin-mediated SREBP pathway. Here, the hepatocytes were treated with ZJ001 at varied concentrations for $6 \mathrm{~h}$, and $30 \mathrm{nmol} / \mathrm{L}$ of insulin was added for $30 \mathrm{~min}$ before completion of the experiment. ZJ001 down-regulated insulin-stimulated SREBP-2 and SREBP-1c mRNA levels in cultured cells, which is consistent with the effects in the liver of ZJ001-treated mice (Figure 4A, 4B). ZJ001 treatment significantly reduced the DNL of cholesterol and fatty acid in a concentration-dependent manner, which is consistent with the changes in gene expression (Figure 4C, 4D). Taken together, our data suggest that ZJ001 decreased SREBP mRNAs and their target gene expression, thereby down-regulating cholesterol and fatty acid biosynthesis and consequently decreasing cellular lipid levels.

\section{ZJ001 suppressed mTORC1 activity.}

ZJ001 treatment reduced the protein levels of the cytosolic precursor form of pre-SREBP-1c and nuclear n-SREBP-1c, in accordance with the decrease in mRNA of SREBP-1c (Figure 5A). However, ZJ001 did not alter the phosphorylation levels of SREBP-1c (Figure S3). Porstmann et al ${ }^{[38]}$ showed that the enhancing effect of insulin on SREBP-1c mRNA is abolished by RNAi-mediated knockdown of mTOR, a main component of mTORC1. mTORC1 also includes Raptor, which acts as a scaffold to recruit downstream substrates, such as eukaryotic initiating factor $4 \mathrm{E}$ binding protein 1 (4E-BP1) and p70S6K, that contribute to mTORC1-dependent regulation of protein translation ${ }^{[39]}$. mTOR is phosphorylated at Ser2448 via the PI3K/AKT signal pathway and auto-phosphorylated at Ser2481 ${ }^{[40,41]}$. Given that ZJ001 decreased SREBP mRNA and in insulin-treatment hepatocytes, we used rat primary hepatocytes to further investigate whether ZJ001 modulated insulinmediated PI3KAKT/mTORC1 pathway in hepatocytes. We observed a decrease in phosphorylated levels of mTOR after ZJ001 treatment at the cellular level (Figure 5B). Accordingly, ZJ001 treatment also blocked the activity of p70S6K, one of the major downstream targets of mTORC1, as evidenced by the decline of S6 phosphorylation levels (Figure 5B). Studies have shown that insulin activates mTORC1 through AKTmediated phosphorylation of TSC2, thereby inhibiting TSC1/2 function ${ }^{[42]}$. TSC1/2 suppress Rheb (Ras Homolog Enriched 
A
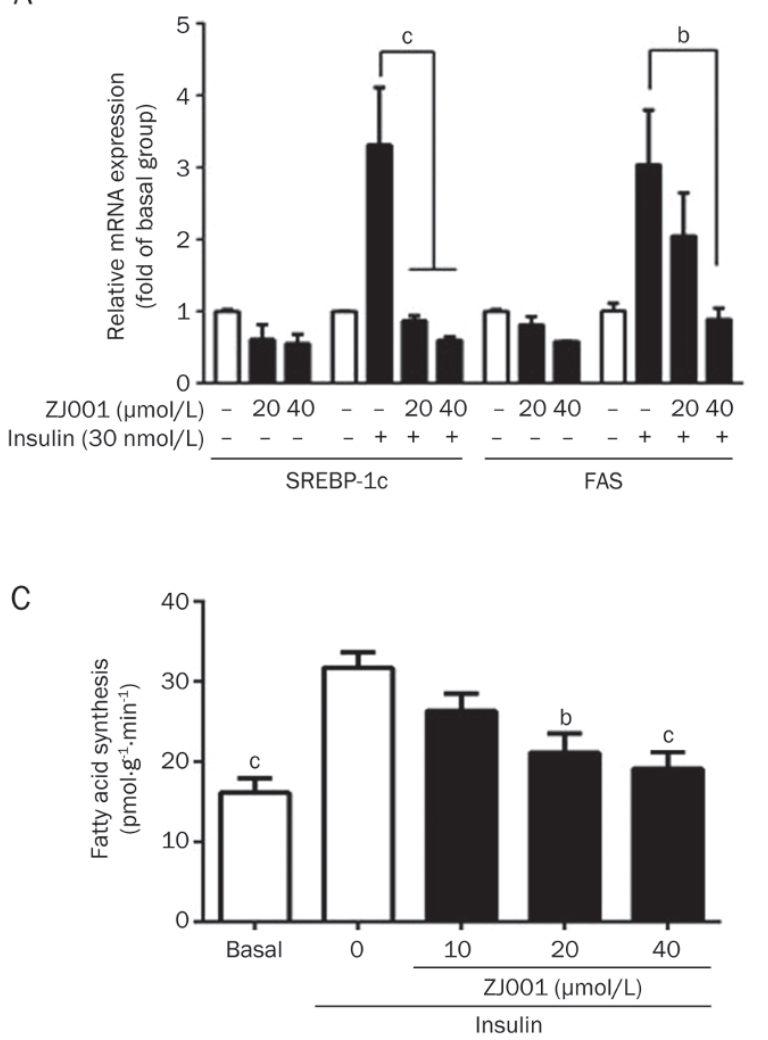

B
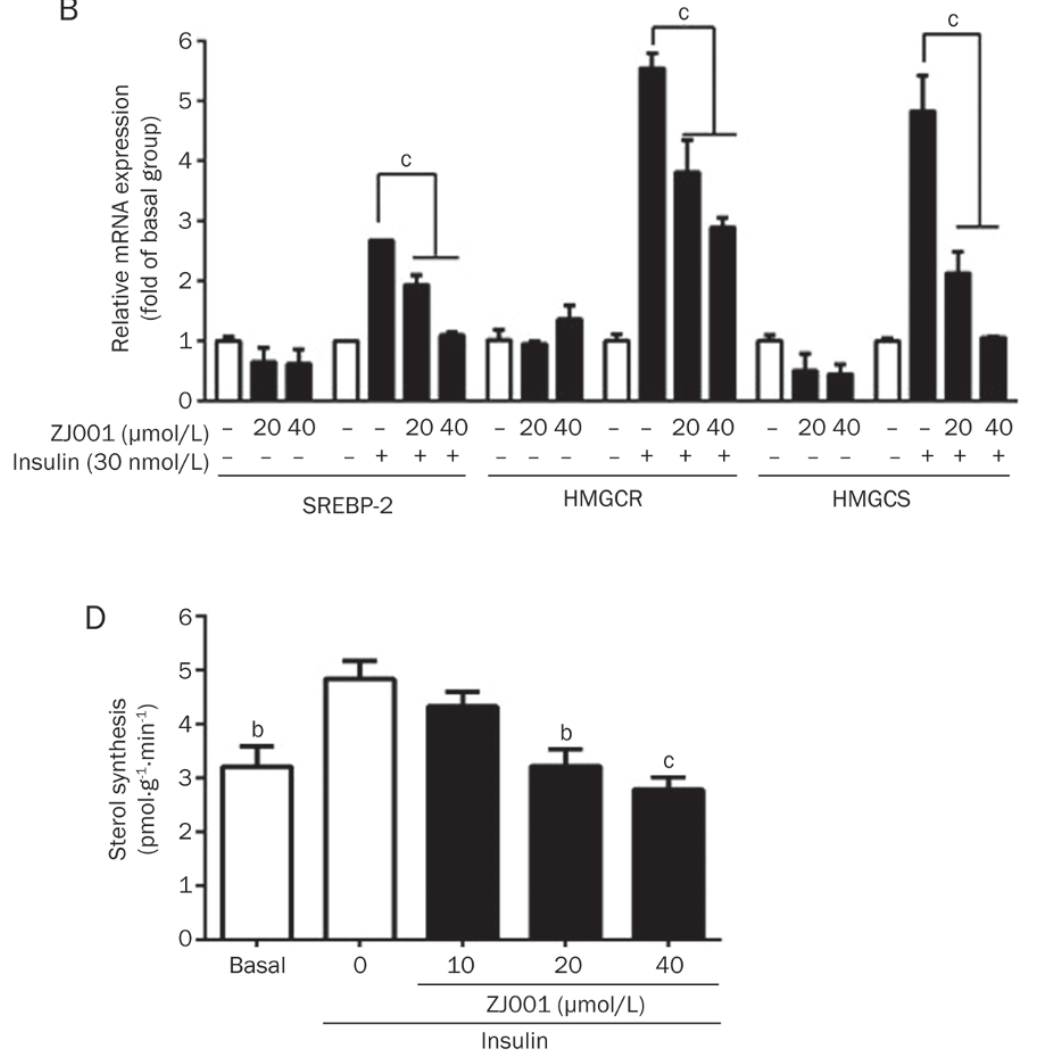

Figure 4. ZJ001 inhibited the biosynthesis of cholesterol and fatty acid by decreasing SREBPs target genes in primary hepatocytes. (A and B) Expression of genes involved in lipid synthesis in primary hepatocytes. Primary hepatocytes were starved for $16 \mathrm{~h}$ and incubated in DMEM supplemented with increasing concentrations of ZJ001 for $6 \mathrm{~h}$, followed by the absence or presence of $30 \mathrm{nmol} / \mathrm{L}$ insulin for $30 \mathrm{~min}$ before completion of the experiment. The cells were lysed in Trizol reagents, and RNA samples were extracted according to the manufacturer's protocol. The expression of multiple genes was analyzed using reverse transcription followed by quantitative-PCR (Q-PCR). (C and D) ZJ001 inhibited de novo lipid synthesis in insulin-treated hepatocyte. Fatty acid (C) and cholesterol (D) were extracted, and lipid synthesis was measured. The results are shown as the mean $\pm \operatorname{SEM}(n=3)$, and all experiments were repeated three times. ${ }^{b} P<0.05,{ }^{c} P<0.01$ compared with the control group.

in Brain), which phosphorylates and activates $\operatorname{mTOR}^{[43,44]}$. However, insulin induced phosphorylation of AKT and ZJ001 did not block TSC2, which suggests that alternative proteins upstream of mTORC1 are involved. The other branch of AKT, GSK3, was also not altered (Figure 5B).

AMPK responds to energy stress by suppressing cell growth and biosynthetic processes partially through its inhibition of the rapamycin-sensitive mTORC1 pathway ${ }^{[20]}$. Hence, we investigated the effect of ZJ001 on the AMPK pathway. As expected, the phosphorylation of AMPK and its direct downstream protein, ACC, were significantly increased in hepatocytes after ZJ001 treatment. However, ZJ001 did not alter TSC2. We observed increased Raptor phosphorylation, which is required for the inhibition of mTORC1. These results may indicate that the activation of AMPK and subsequent phosphorylation of Raptor by ZJ001 potentially inhibited mTORC1 (Figure 5B, 5C).

ZJ001 suppressed lipid synthesis partially via the AMPK pathway ZJ001 also increased the phosphorylation level of AMPK, ACC and Raptor in non-insulin-treated hepatocytes (Figure 6A).
A commonly used competitive AMPK inhibitor, Compound C, was applied to verify the role of AMPK activation in the biological activity of ZJ001. Compound C partially blocked the ZJ001 effect on cholesterol and triglyceride synthesis, suggesting that ZJ001 inhibition of DNL is partially dependent on activation of the AMPK pathway. ZJ001 may exert its lipid-lowing effect through an alternative pathway (Figure $6 \mathrm{~B})$. These results suggest that ZJ001 regulates lipid synthesis partially through AMPK/mTORC1 pathways, which was also exemplified by the elevated ratio of phosphorylation levels to the protein levels of ACC and AMPK and decrease in the phosphorylation levels of mTOR in vivo (Figure 6C).

We investigated the direct activation of ZJ001 on recombinant AMPK heterotrimers, but no obvious activation was observed (data not shown). AMPK is a highly conserved sensor of cellular energy status that is activated when the AMP/ ATP ratio is increased ${ }^{[45]}$. Because the AMP level was too low to be measured accurately by our HPLC, we investigated the ADP/ATP ratio in rat primary hepatocytes. The results showed that ZJ001 dose-dependently increased the ADP/ATP ratio (Figure 6D). Mitochondria are a subcellular organelle in 
A

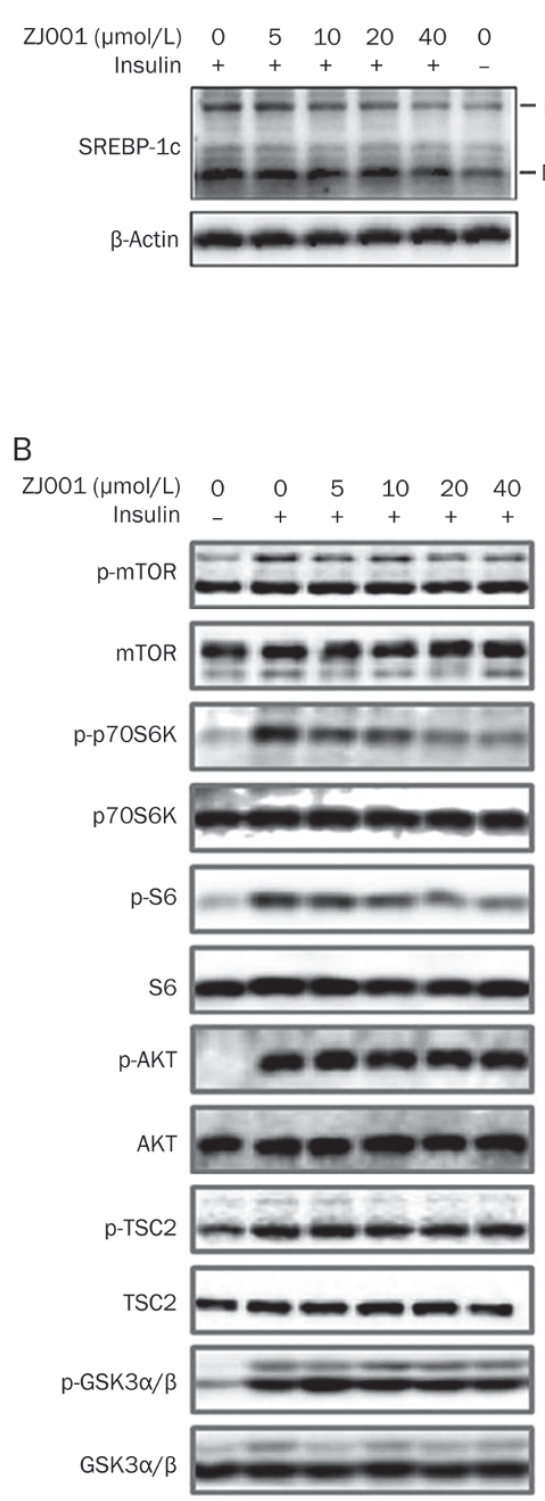

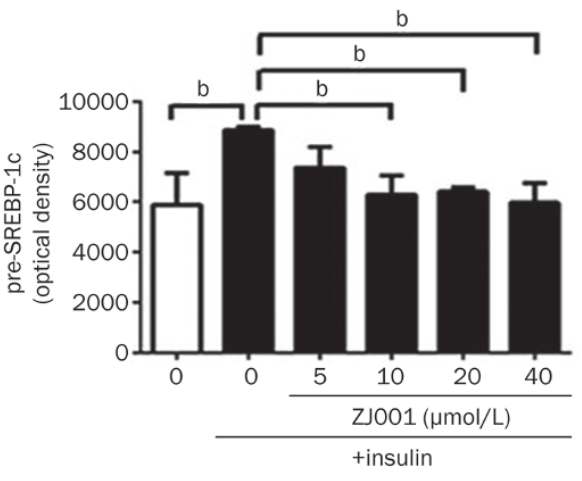
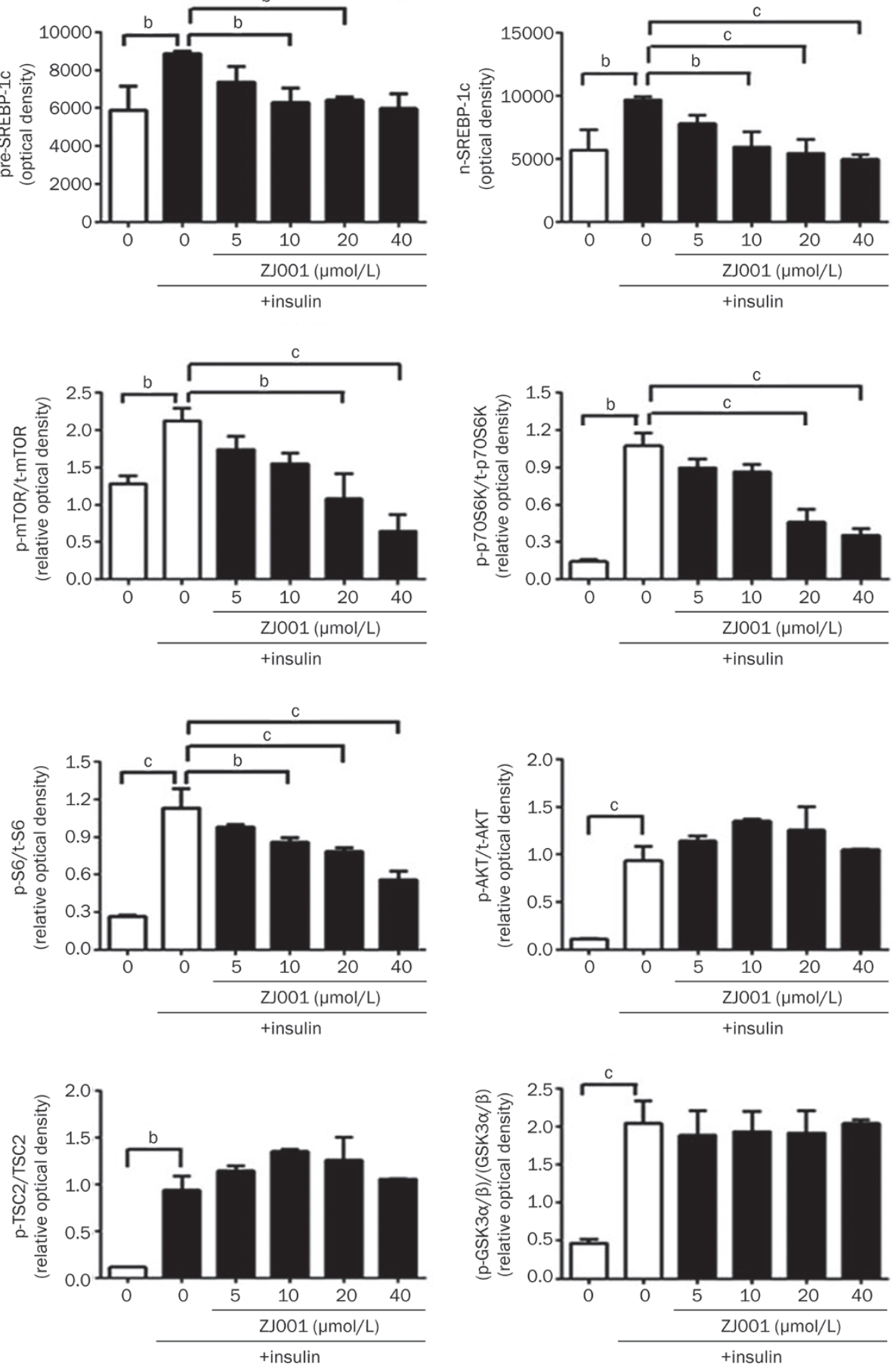

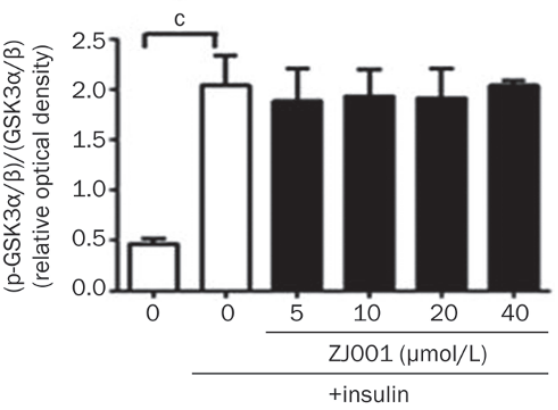

Figure 5A-5B. ZJ001 suppressed mTORC1 activity. Primary hepatocytes from rat were prepared and plated on $\mathrm{d} 0$. On $\mathrm{d} 1$, cells were treated with ZJ001 for $6 \mathrm{~h}$, the cells were then treated with $30 \mathrm{nmol} / \mathrm{L}$ insulin for $30 \mathrm{~min}$, harvested, and lysed. Each sample was subjected to immunoblot analyses. (A) The protein level of n-SREBP-1c (N) and pre-SREBP-1c (P), the optical density were calculated using Image J software ( $n=3)$. (B) The phosphorylation and protein levels of mTOR, p70S6K, S6, AKT, TSC2, and GSK3 $\alpha / \beta$. The ratio of the phosphorylation level to the protein level was determined ( $n=3$ ). ${ }^{\mathrm{b}} P<0.05,{ }^{\mathrm{C}} \mathrm{P}<0.01$ compared with the control group.

which fatty acids and glucose are used for the production of ATP through the oxidative phosphorylation system ${ }^{[46]}$. ZJ001 significantly increased the $\mathrm{O}_{2}$ consumption rate in human HepG2 hepatic cells (Figure 6E). This block was rather mild in rat primary hepatocytes and isolated mitochondria from rat liver (Figure 6F, 6G), which suggests that ZJ001 may stimulate the cellular energy sensor AMPK via a mild uncoupling of the mitochondria electron respiration chain to decrease intracellu- 
C
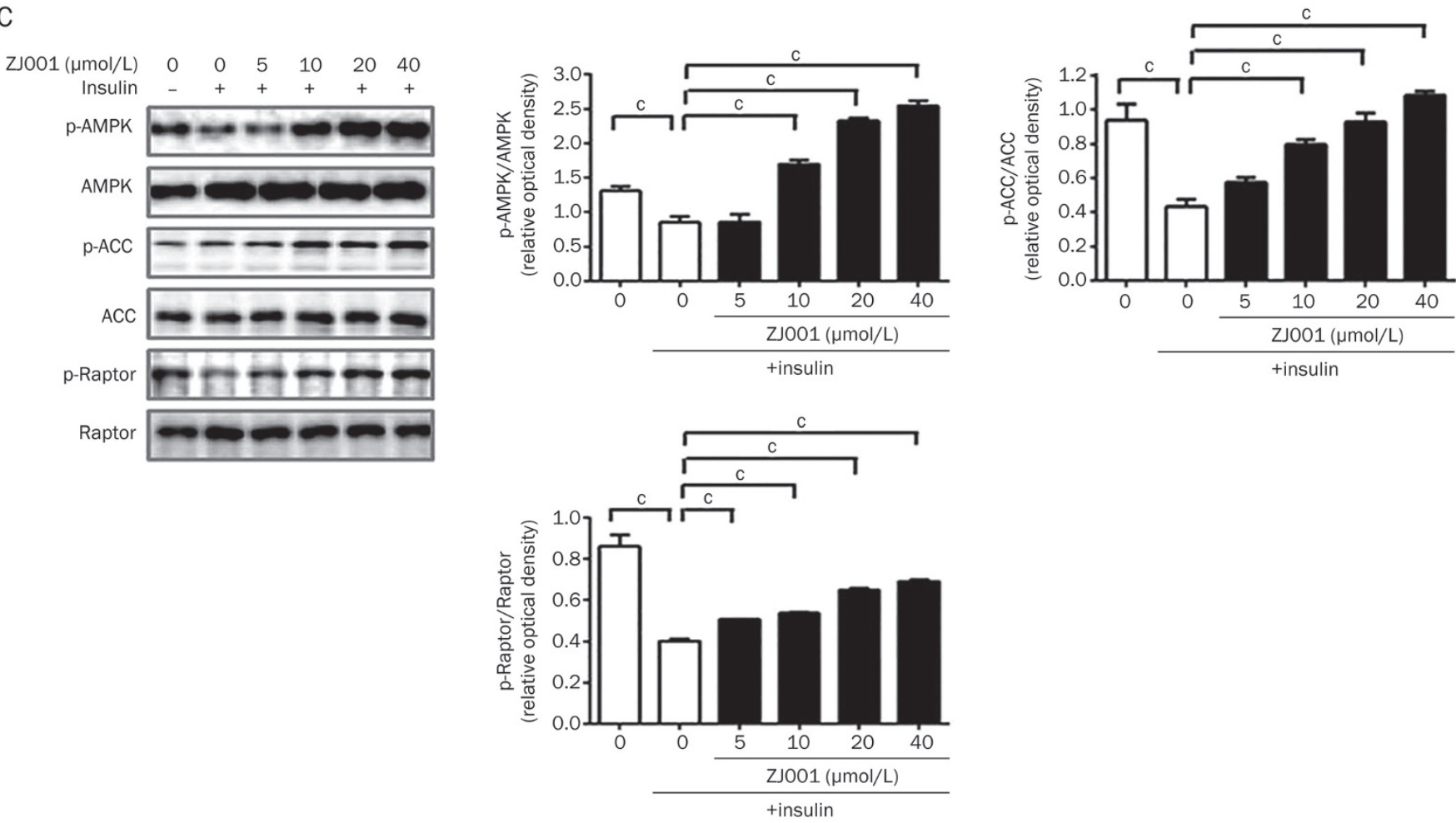

Figure 5C. (C) The phosphorylation and protein levels of AMPK, ACC, and Raptor. The ratio of the phosphorylation level to the protein level was determined $(n=3) .{ }^{b} P<0.05,{ }^{C} P<0.01$ compared with the control group.

lar ATP production.

\section{Discussion}

Currently, most drugs for the treatment of lipid-related metabolic disorders target rate-limiting enzymes involved in lipogenesis, such as FAS, which is a key enzyme in fatty acid synthesis; DGAT (acyl CoA: diacylgycerol acyltransferase), which catalyzes the final step, is the only key and ratelimiting enzyme in triglyceride synthesis ${ }^{[47]}$. However, the total or partial inhibition of rate-limiting enzymes may result in two adverse issues: the accumulation of substrate may cause lysosomal storage disease ${ }^{[48]}$ and the reduction of product will cause compensatory action. SREBPs directly activate the expression of more than 30 genes dedicated to the synthesis and uptake of cholesterol, fatty acids, triglycerides, and phospholipids ${ }^{[11]}$. The mechanisms of inactivating rate-limit enzymes that are involved in lipogenesis are different from those causing inhibition of SREBPs, which cause a decline in the overall efficiency of lipogenesis. Statins are the most widely prescribed drugs for the treatment of hypercholesterolemia, and these drugs inhibit HMG-CoA reductase, which catalyzes the rate-limiting step in cholesterol biosynthesis. Decreased cholesterol biosynthesis increases LDL-receptor levels, which results in a positive cycle for lowered cholesterol levels in serum. However, statins cannot decrease fatty acid biosynthesis because they block the cholesterol biosynthesis that stimulates SREBP activity ${ }^{[36]}$. The above deficiency of the statin drugs might be compensated for if candidates that spe- cifically modulate the SREBP pathway are identified.

Here, we used a cell-based reporter assay to screen for compounds that regulate SRE-containing promoters, and we found a small molecule, ZJ001. As expected, ZJ001 treatment decreased triglyceride and cholesterol synthesis in vitro and in vivo, with down-regulated expression of SREBP and crucial genes involved in lipogenesis. Chronic ZJ001 treatment improved lipid metabolism in dietary obese mice. These findings of ZJ001 proved the concept that inhibition of the SREBP pathway may be a potential strategy to treat metabolic diseases.

Regulation of SREBP occurs at two levels: transcriptional regulation of SREBP mRNA and posttranscriptional regulation of precursor SREBP protein. Posttranscriptional regulation involves the sterol-mediated suppression of SREBP cleavage $^{[49,50]}$. The transcriptional regulation of the SREBP mRNA is more complex. SREBP-1c and SREBP-2 are subject to distinct forms of transcriptional regulation, whereas SREBP1a appears to be constitutively expressed at low levels in liver and most other tissues of adult animals ${ }^{[51]}$. One mechanism of regulation that is shared by SREBP-1c and SREBP-2 involves a feed-forward regulation mediated by SREs that are present in the enhancer/promoters of each gene. This feed-forward loop processes mature n-SREBP, which activates the transcription of their own genes ${ }^{[52,53]}$.

AMPK negatively regulates hepatic SREBP-1c activity partially through its inhibition of mTORC1. There is another way that AMPK modulates SREBP-1c activity. Yu Li et al showed 
$\begin{array}{lllllll}\text { A } \quad Z 001(\mu \mathrm{mol} / \mathrm{L}) & 0 & 5 & 10 & 20 & 40\end{array}$
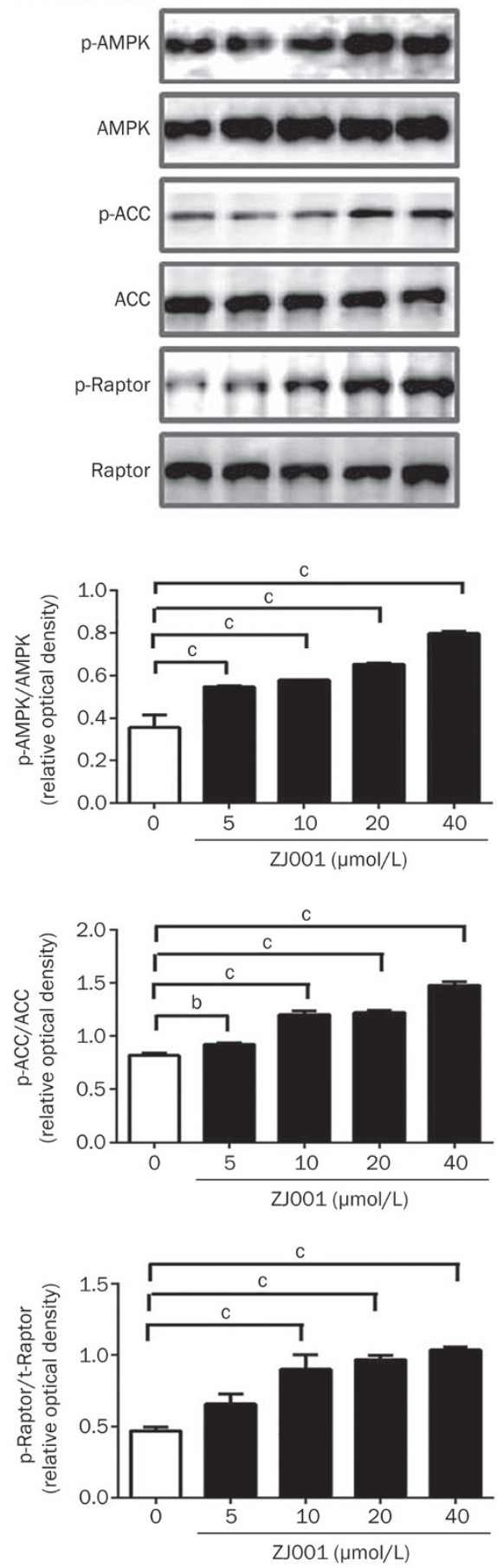

B

$\mathrm{ZJ001}(\mu \mathrm{mol} / \mathrm{L})$

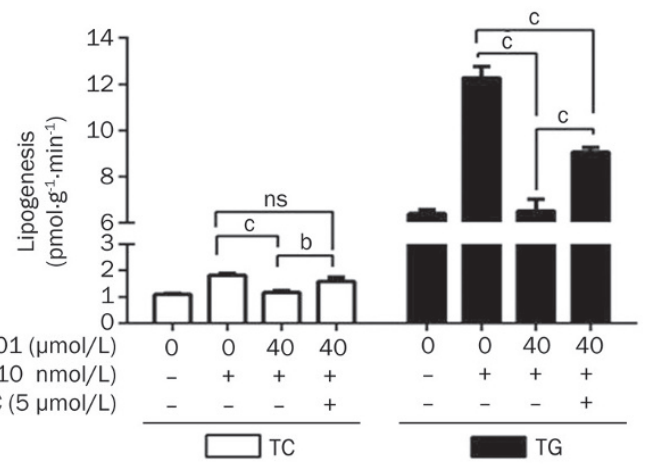

C
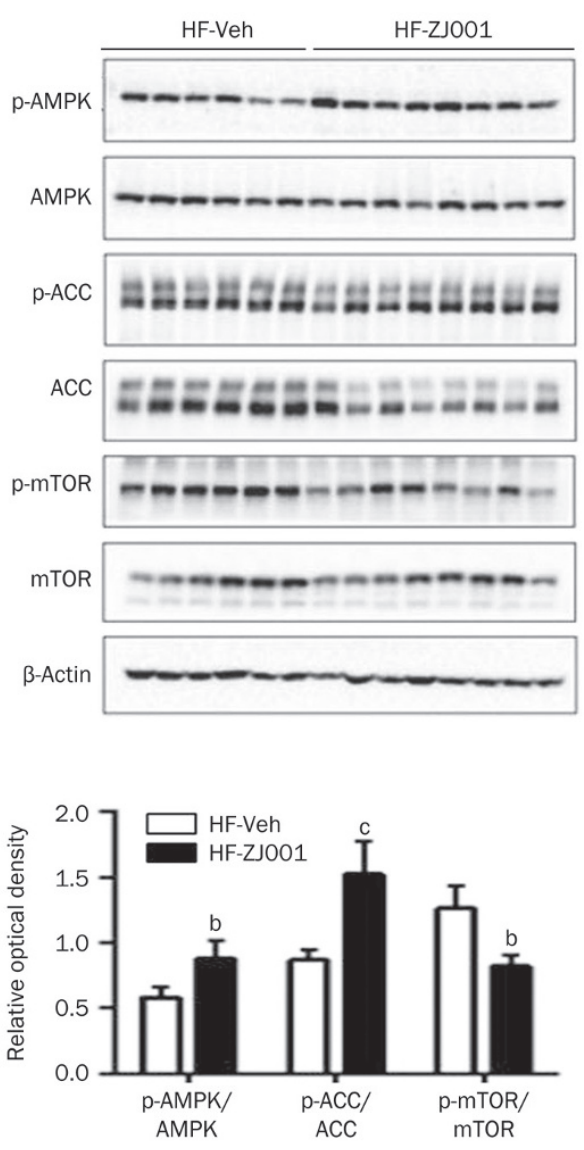

Figure 6A-6C. ZJ001 suppressed lipid synthesis partially via the AMPK pathway. (A) Similar ZJ001 treatment as Figure 5 without insulin stimulation. Each sample was subjected to immunoblot analyses of the phosphorylation level and total protein levels of AMPK, ACC and Raptor. (B) Hepatocytes were pre-incubated for $30 \mathrm{~min}$ in the absence or presence of Compound $\mathrm{C}(5 \mu \mathrm{mol} / \mathrm{L})$ and treated with $40 \mu \mathrm{mol} / \mathrm{L} \mathrm{ZJ001} \mathrm{for} 20 \mathrm{~h}$, followed by lipid synthesis measurement. (C) mTOR, AMPK, and ACC phosphorylation in the liver of mice fed a high-fat diet. The ratio of the phosphorylation to total protein levels of AMPK, ACC, and mTOR were calculated based on the intensity detected using the Image J software. The results are shown as the mean \pm SEM. ${ }^{b} P<0.05,{ }^{c} P<0.01$ compared with the control group.

that AMPK directly phosphorylates and inhibits SREBP activity to attenuate hepatic steatosis and atherosclerosis in dietinduced insulin-resistant mice ${ }^{[54]}$. ZJ001 increased AMPK phosphorylation and its direct downstream proteins, ACC and Raptor, in hepatocytes after ZJ001 treatment. However, ZJ001 did not alter the phosphorylation levels of SREBP-1c 

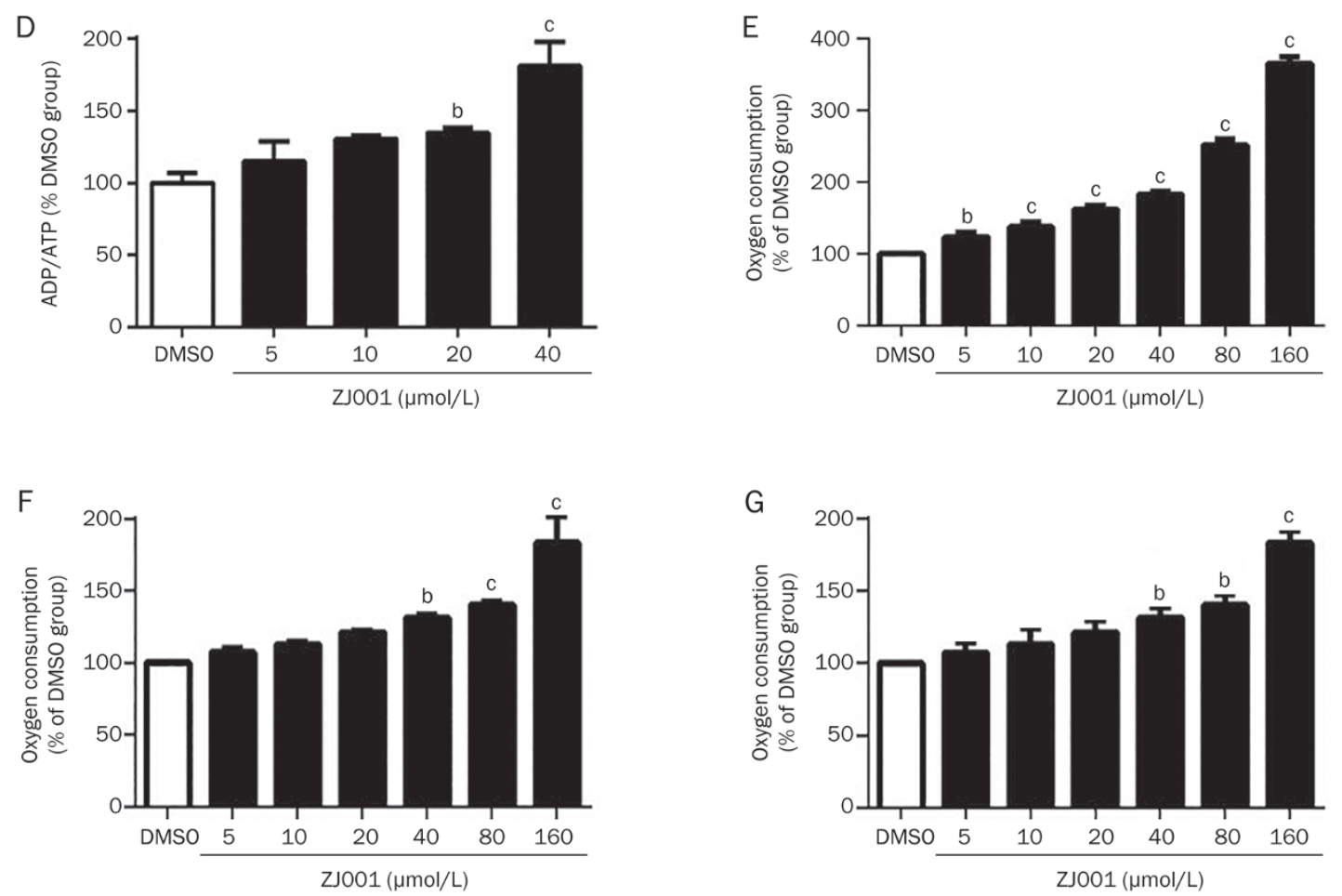

Figure 6D-6G. (D) Effect of ZJ001 on the ADP/ATP ratio after incubation for $1 \mathrm{~h}$ in rat primary hepatocytes $(n=3)$. The effect of ZJ001 on $\mathrm{O}_{2}$ consumption in HepG2 (E), primary hepatocytes $(F)$ and the isolated mitochondria from rat liver $(G)$. The results are shown as the mean \pm SEM. ${ }^{b} P<0.05$, ${ }^{c} P<0.01$ compared with the control group.

(Figure S3), indicating that the inhibition of lipid synthesis by ZJ001 probably occurs through mTORC1. ACC is a biotincontaining enzyme that catalyzes the carboxylation of acetylCoA to malonyl-CoA, which is the rate-limiting step in fatty acid synthesis ${ }^{[55]}$. SREBP-1c activates the transcription level of ACC gene expression ${ }^{[10]}$. The total ACC protein level was significantly decreased in liver after chronic ZJ001 treatment (Figure 6C). Taken together, ZJ001 reduced fatty acid synthesis at least partially through regulation of the AMPK/mTORC1/ SREBP-1c axis.

As one of the major downstream target of mTORC1, p70S6K, which phosphorylates the ribosomal protein S6, was also blocked by ZJ001. A previous study showed that p70S6K is also required for insulin stimulation of SREBP processing in rat hepatocytes ${ }^{[17]}$. However, it has been difficult to dissect the effect of ZJ001 on SREBP processing from mRNA transcription because the reduction of SREBP mRNA and the decrease of precursor protein levels were concomitant. The individual effect of ZJ001 on the transcriptional regulation of SREBP mRNA and SREBP processing remains to be elucidated.

In conclusion, we identified a small-molecule, ZJ001, that inhibited triglyceride and cholesterol content in vivo and in vitro. ZJ001 showed multiple beneficial effects in vivo, suggesting that modulation of the SREBP-1c pathway could be a potential therapeutic target for the treatment of lipid metabolic disorders.

\section{Acknowledgements}

This work was supported by a grant from National Program on Key Basic Research Project (973 Program; 2012CB524906), National Science and Technology Major Projects for "Major New Drugs Innovation and Development" (2012ZX09301001004), and the National Natural Science Foundation of China (81125023, 81270942, and 81001463).

We thank Tian-cheng DONG for his assistance in the animal experiments.

\section{Author contribution}

Jia LI, Fan YANG, Jie TANG, and Jing-ya LI designed the research; Jin ZHANG, Dong-mei CHEN, Ling-ling YANG, Chun-mei XIA, Hao-wen JIANG, Chun-lan TANG, and Zhi$\mathrm{fu}$ XIE performed the research; Feng ZHANG synthesized the compound; and Jin ZHANG, Li-na ZHANG, and Yan-yun FU analyzed the data and wrote the paper.

\section{Supplementary information}

Supplementary information is available at (APS)'s website.

\section{References}

1 Unger RH. Lipotoxic diseases. Annu Rev Med 2002; 53: 319-36.

2 Donnelly KL, Smith Cl, Schwarzenberg SJ, Jessurun J, Boldt MD, Parks EJ. Sources of fatty acids stored in liver and secreted via lipoproteins in patients with nonalcoholic fatty liver disease. J Clin Invest 2005; 
115: 1343-51.

3 Choi SS, Diehl AM. Hepatic triglyceride synthesis and nonalcoholic fatty liver disease. Curr Opin Lipidol 2008; 19: 295-300.

4 Brewer M, Lange D, Baler R, Anzulovich A. SREBP-1 as a transcriptional integrator of circadian and nutritional cues in the liver. J Biol Rhythm 2005; 20: 195-205.

5 Kohjima M, Higuchi N, Kato M, Kotoh K, Yoshimoto T, Fujino T, et al. SREBP-1c, regulated by the insulin and AMPK signaling pathways, plays a role in nonalcoholic fatty liver disease. Int J Mol Med 2008; 21: 507-11.

6 Yang ZX, Sun H, Shen W. Expression and action of hepatic sterol regulatory element-binding protein-1c in patients with nonalcoholic fatty liver disease. Zhonghua Gan Zang Bing Za Zhi 2008; 16: 823-6. Chinese.

7 Shimomura I, Hammer RE, Ikemoto S, Brown MS, Goldstein JL. Leptin reverses insulin resistance and diabetes mellitus in mice with congenital lipodystrophy. Nature 1999; 401: 73-6.

8 Shimano H, Horton JD, Shimomura I, Hammer RE, Brown MS, Goldstein JL. Isoform $1 \mathrm{c}$ of sterol regulatory element binding protein is less active than isoform $1 \mathrm{a}$ in livers of transgenic mice and in cultured cells. J Clin Invest 1997; 99: 846-54.

9 Knebel B, Haas J, Hartwig S, Jacob S, Kollmer C, Nitzgen U, et al. Liver-specific expression of transcriptionally active SREBP-1c is associated with fatty liver and increased visceral fat mass. Plos One 2012; 7: e31812.

10 Liang GS, Yang J, Horton JD, Hammer RE, Goldstein JL, Brown MS. Diminished hepatic response to fasting/refeeding and liver $\mathrm{X}$ receptor agonists in mice with selective deficiency of sterol regulatory elementbinding protein-1c. J Biol Chem 2002; 277: 9520-8.

11 Horton JD, Goldstein JL, Brown MS. SREBPs: activators of the complete program of cholesterol and fatty acid synthesis in the liver. J Clin Invest 2002; 109: 1125-31.

12 Rawson RB. The SREBP pathway - insights from Insigs and insects. Nat Rev Mol Cell Biol 2003; 4: 631-40.

13 Amemiya-Kudo M, Shimano H, Yoshikawa T, Yahagi N, Hasty AH, Okazaki $\mathrm{H}$, et al. Promoter analysis of the mouse sterol regulatory element-binding protein-1c gene. J Biol Chem 2000; 275: 31078-85.

14 Chen GX, Liang GS, Ou JF, Goldstein JL, Brown MS. Central role for liver $X$ receptor in insulin-mediated activation of Srebp-1c transcription and stimulation of fatty acid synthesis in liver. Proc Natl Acad Sci U S A 2004; 101: 11245-50.

15 Pal I, Mandal M. PI3K and Akt as molecular targets for cancer therapy: current clinical outcomes. Acta Pharmacol Sin 2012; 33: 1441-58.

16 Li S, Brown MS, Goldstein JL. Bifurcation of insulin signaling pathway in rat liver: mTORC1 required for stimulation of lipogenesis, but not inhibition of gluconeogenesis. Proc Natl Acad Sci U S A 2010; 107: 3441-6.

17 Owen JL, Zhang YY, Bae SH, Farooqi MS, Liang GS, Hammer RE, et al. Insulin stimulation of SREBP-1c processing in transgenic rat hepatocytes requires p70 S6-kinase. Proc Natl Acad Sci U S A 2012; 109: 16184-9.

18 Bengoechea-Alonso MT, Ericsson J. A phosphorylation cascade controls the degradation of active SREBP1. J Biol Chem 2009; 284: 5885-95.

19 Punga T, Bengoechea-Alonso MT, Ericsson J. Phosphorylation and ubiquitination of the transcription factor sterol regulatory elementbinding protein-1 in response to DNA binding. J Biol Chem 2006; 281: 25278-86.

20 Liu XN, Chhipa RR, Pooya S, Wortman M, Yachyshin S, Chow LML, et al. Discrete mechanisms of mTOR and cell cycle regulation by AMPK agonists independent of AMPK. Proc Natl Acad Sci U S A 2014; 111: E435-44.

21 Hardie DG. AMPK: a key regulator of energy balance in the single cell and the whole organism. Int J Obes (Lond) 2008; 32: S7-12.

22 Assifi MM, Suchankova G, Constant S, Prentki M, Saha AK, Ruderman NB. AMP-activated protein kinase and coordination of hepatic fatty acid metabolism of starved/carbohydrate-refed rats. Am J Physiol Endocrinol Metab 2005; 289: E794-800.

23 Gwinn DM, Shackelford DB, Egan DF, Mihaylova MM, Mery A, Vasquez DS, et al. AMPK phosphorylation of raptor mediates a metabolic checkpoint. Mol Cell 2008; 30: 214-26.

24 Seglen PO. Preparation of isolated rat liver cells. Methods Cell Biol 1976; 13: 29-83.

$25 \mathrm{Kim} \mathrm{JB}$, Spiegelman BM. ADD1/SREBP1 promotes adipocyte differentiation and gene expression linked to fatty acid metabolism. Genes Dev 1996; 10: 1096-107.

26 Luo C, Long J, Liu J. An improved spectrophotometric method for a more specific and accurate assay of mitochondrial complex III activity. Clin Chim Acta 2008; 395: 38-41.

27 Frezza C, Cipolat S, Scorrano L. Organelle isolation: functional mitochondria from mouse liver, muscle and cultured fibroblasts. Nature Protoc 2007; 2: 287-95.

28 Turner N, Li JY, Gosby A, To SW, Cheng Z, Miyoshi H, et al. Berberine and its more biologically available derivative, dihydroberberine, inhibit mitochondrial respiratory complex I: a mechanism for the action of berberine to activate AMP-activated protein kinase and improve insulin action. Diabetes 2008; 57: 1414-8.

29 Vichai V, Kirtikara K. Sulforhodamine B colorimetric assay for cytotoxicity screening. Nature Protoc 2006; 1: 1112-6.

30 Folch J, Lees M, Sloane Stanley GH. A simple method for the isolation and purification of total lipides from animal tissues. J Biol Chem 1957; 226: 497-509.

31 Zhang LN, Xu L, Zhou HY, Wu LY, Li YY, Pang T, et al. Novel smallmolecule AMP-activated protein kinase allosteric activator with beneficial effects in $d b / d b$ mice. PloS One 2013; 8: e72092.

32 Magana MM, Osborne TF. Two tandem binding sites for sterol regulatory element binding proteins are required for sterol regulation of fatty-acid synthase promoter. J Biol Chem 1996; 271: 32689-94.

33 Pyörälä K, De Backer G, Graham I, Poole-Wilson P, Wood D. Prevention of coronary heart disease in clinical practice: recommendations of the task force of the European Society of Cardiology, European Atherosclerosis Society and European Society of Hypertension. Atherosclerosis 1994; 110: 121-61.

34 Postic C, Girard J. Contribution of de novo fatty acid synthesis to hepatic steatosis and insulin resistance: lessons from genetically engineered mice. J Clin Invest 2008; 118: 829-38.

35 Shimomura I, Bashmakov Y, Horton JD. Increased levels of nuclear SREBP-1c associated with fatty livers in two mouse models of diabetes mellitus. J Biol Chem 1999; 274: 30028-32.

36 Tang JJ, Li JG, Qi W, Qiu WW, Li PS, Li BL, et al. Inhibition of SREBP by a small molecule, betulin, improves hyperlipidemia and insulin resistance and reduces atherosclerotic plaques. Cell Metab 2011; 13: 44-56.

37 Leavens KF, Birnbaum MJ. Insulin signaling to hepatic lipid metabolism in health and disease. Crit Rev Biochem Mol Biol 2011; 46: 200-15.

38 Porstmann T, Santos CR, Griffiths B, Cully M, Wu M, Leevers S, et al. SREBP activity is regulated by mTORC1 and contributes to Aktdependent cell growth. Cell Metab 2008; 8: 224-36.

39 Chapuis N, Tamburini J, Green AS, Willems L, Bardet V, Park S, et al. Perspectives on inhibiting mTOR as a future treatment strategy for 
hematological malignancies. Leukemia 2010; 24: 1686-99.

40 Nave BT, Ouwens DM, Withers DJ, Alessi DR, Shepherd PR. Mammalian target of rapamycin is a direct target for protein kinase B: identification of a convergence point for opposing effects of insulin and amino-acid deficiency on protein translation. Biochem J 1999; 344: 427-31.

41 Peterson RT, Beal PA, Comb MJ, Schreiber SL. FKBP12-rapamycinassociated protein (FRAP) autophosphorylates at serine 2481 under translationally repressive conditions. J Biol Chem 2000; 275: 741623.

42 DeYoung MP, Horak P, Sofer A, Sgroi D, Ellisen LW. Hypoxia regulates TSC1/2-mTOR signaling and tumor suppression through REDD1mediated 14-3-3 shuttling. Gene Dev 2008; 22: 239-51.

43 Tee AR, Manning BD, Roux PP, Cantley LC, Blenis J. Tuberous sclerosis complex gene products, tuberin and hamartin, control mTOR signaling by acting as a GTPase-activating protein complex toward Rheb. Curr Biol 2003; 13: 1259-68.

44 Inoki K, Li Y, Xu T, Guan KL. Rheb GTPase is a direct target of TSC2 GAP activity and regulates mTOR signaling. Gene Dev 2003; 17 : 1829-34.

45 Hardie DG. AMP-activated protein kinase-an energy sensor that regulates all aspects of cell function. Gene Dev 2011; 25: 1895908.

46 Green DE. Electron transport and oxidative phosphorylation. Adv Enzymol Rel S Bi 1959; 21: 73-129.

47 Harris CA, Haas JT, Streeper RS, Stone SJ, Kumari M, Yang K, et al. DGAT enzymes are required for triacylglycerol synthesis and lipid droplets in adipocytes. J Lipid Res 2011; 52: 657-67.

48 Cox TM. Substrate reduction therapy for lysosomal storage diseases. Acta Paediatr Suppl 2005; 94: 69-75.

49 Shimomura I, Bashmakov Y, Shimano H, Horton JD, Goldstein JL, Brown MS. Cholesterol feeding reduces nuclear forms of sterol regulatory element binding proteins in hamster liver. Proc Natl Acad Sci U S A 1997; 94: 12354-9.

50 Brown MS, Goldstein JL. The SREBP pathway: regulation of cholesterol metabolism by proteolysis of a membrane-bound transcription factor. Cell 1997; 89: 331-40.

51 Shimomura I, Shimano H, Horton JD, Goldstein JL, Brown MS. Differential expression of exons $1 \mathrm{a}$ and $1 \mathrm{c}$ in mRNAs for sterol regulatory element binding protein-1 in human and mouse organs and cultured cells. J Clin Invest 1997; 99: 838-45.

52 Sato R, Inoue J, Kawabe Y, Kodama T, Takano T, Maeda M. Steroldependent transcriptional regulation of sterol regulatory elementbinding protein-2. J Biol Chem 1996; 271: 26461-4.

53 Amemiya-Kudo M, Shimano H, Yoshikawa T, Yahagi N, Hasty AH, Okazaki $\mathrm{H}$, et al. Promoter analysis of the mouse sterol regulatory element-binding protein-1c gene. J Biol Chem 2000; 275: 31078-85.

54 Li Y, Xu S, Mihaylova MM, Zheng B, Hou X, Jiang B, et al. AMPK phosphorylates and inhibits SREBP activity to attenuate hepatic steatosis and atherosclerosis in diet-induced insulin-resistant mice. Cell Metab 2011; 13: 376-88.

55 Wakil SJ, Stoops JK, Joshi VC. Fatty acid synthesis and its regulation. Annu Rev Biochem 1983; 52: 537-79. 